\title{
A Method for the Measurement of Lutein in Infant Formula
}

\author{
Rebecca Yuhas ${ }^{1}$, Megan McCormick ${ }^{1}$, Stephen Yachetti ${ }^{1}$, Anita M. Burgher ${ }^{1}$, Kadeline Kong ${ }^{2}$, \\ John Walsh ${ }^{3}$
}

\footnotetext{
${ }^{1}$ Department of Nutrition Research, Pfizer Nutrition, Pennsylvania, USA;

${ }^{2}$ Department of Quality, Wyeth Nutrition (S) Pte Lt, Singapore;

${ }^{3}$ Department of Quality, Wyeth Nutritionals Ltd., Askeaton, County Limerick, Ireland.

E-mail: rebecca.yuhas@pfizer.com
}

Received October $21^{\text {st }}, 2010$; revised January $14^{\text {th }}, 2011$; accepted February $24^{\text {th }}, 2011$.

\begin{abstract}
Lutein is an antioxidant that is deposited in the macular region of the eye and is crucial to macular function. Lutein is present in human milk and recently has been added to infant and toddler formulas. A method for the extraction and quantification of lutein from lutein-fortified infant formula and toddler milk products was developed. The lipids and carotenoids were extracted from the samples with ethanol and hexane: tetrahydrofuran. Polar xanthophylls were extracted from the organic mixture with ethanol: water, leaving behind lipids and less polar carotenoids. The ethanol: water extracts were dried, reconstituted in mobile phase, and the lutein was quantified by high performance liquid chromatography with UV detection. A C30 carotenoid column and a mobile phase gradient of methyl-tert-butyl ether and methanol were used for the chromatographic separation. Validation data showed repeatability with relative standard deviations $<4 \%$ and intermediate precision with relative standard deviations $<20 \%$ at a low fortification level, 25 $\mathrm{mcg}$ lutein/L, and $<12 \%$ at a high fortification level, $200 \mathrm{mcg}$ lutein/L. Overall recoveries from sample matrix ranged from $88 \%$ to $106 \%$. This liquid:liquid extraction method for the quantification of lutein in infant formulas is precise and accurate.
\end{abstract}

Keywords: Lutein, HPLC, Infant Formula, Carotenoids

\section{Introduction}

The nutritional intake of the neonatal infant must support a period of rapid maturation and organ growth. Human milk is ideally suited to provide the nutritional needs of the infant and contains many bioactive components including carotenoids [1,2]. The xanthophyllic carotenoids, lutein and zeaxanthin must be obtained from dietary sources as they cannot be synthesized by the human body [3]. They occur naturally in human milk [4], but not in infant formulas. Lutein and zeaxanthin are antioxidants that are deposited in the macular region of the eye and are crucial to macular function. These yellow pigmented macular carotenoids are responsible for the yellow pigment of the macula [5]. They have the ability to absorb high-energy blue light and to act as part of the antioxidant system of the retina [6].

Exposure to blue light at any age may cause eye damage and infants and children are at the highest risk. The lens of the neonate is transparent thus providing little protection against this high energy light [6]. As the lens gradually and naturally yellows, the level of blue light reaching the retina is progressively reduced [6,7]. Lutein has been shown to help protect the retina from blue light damage in animal models by filtering out this high energy light $[6,8]$. In addition, there is evidence that lutein acts as an antioxidant in the eye $[6,9,10]$ and as macular lutein is located in close proximity to lipid targets susceptible to oxidation by singlet oxygen, it is well suited to act as a biological antioxidant [11].

Lutein levels from a multinational study of carotenoids in human milk found a range of 14.8 - $43.8 \mathrm{mcg}$ lutein/L with an overall mean of $25 \mathrm{mcg} / \mathrm{L}$ [4]. Infant formula, follow on formula and milks for toddlers and young children were formulated to provide a source of lutein and a validated method was necessary to confirm fortification levels.

Due to the high fat content of the matrices, current methods for the measurement of carotenoids in human milk and formulas often use a saponification or enzy- 
matic hydrolysis step followed by an extraction with organic solvents [12-15]. Losses of up to $40 \%$ of the polar carotenoids lutein and zeaxanthin have been reported due to alkaline hydrolysis. [12,13]. Internal standards such as echininone have been used to correct for losses due to hydrolysis [15]. We modified the carotenoids extraction method developed by Schweigert et al. [12] wherein the lutein was extracted prior to the saponification procedure used to recover more lipophilic carotenoids and their esters. The use of echininone as an internal standard was also investigated during the method implementation. The assay performance was demonstrated at two levels of fortification: $25 \mathrm{mcg} / \mathrm{L}$ in term formula and $200 \mathrm{mcg} / \mathrm{L}$ in follow on formula, and milks for toddlers and young children. The method was found to be precise and accurate for the measurement of lutein in infant formula and milk product matrices.

\section{Materials and Methods}

Chemicals, Solvents and Solutions. Lutein was purchased from Indofine Chemical Company (Hillsborough, NJ). Hexane, acetone, methanol and methyl-tert-butylether (MTBE) were HPLC grade obtained from EMD (Darmstadt, Germany). Inhibitor free, anhydrous tetrahydrofuran (THF), 99.9\% purity, was from Sigma-Aldrich (St. Louis, MO). Absolute Ethanol was purchased from Rossville Gold Shield (Haywood, CA). Deionized water was from an internal Millipore purification system, (Billerica, MA). Extraction solvent solutions were: hexane:THF, 80:20, v:v, ethanol:deionized $\mathrm{H}_{2} \mathrm{O}$, 90:10, v:v. Test tubes with Teflon ${ }^{\circledR}$ lined screw caps were used for all extractions.

Standard Preparation. A stock standard solution was prepared by dissolving $2.0 \mathrm{mg}$ lutein in $25 \mathrm{~mL}$ absolute ethanol, stored at $-20^{\circ} \mathrm{C}$ for up to one month. A working standard was prepared by diluting the stock standard solution $1 / 25$ in a volumetric flask with ethanol. This solution was stored in a refrigerator at $10^{\circ} \mathrm{C}$ and used within 5 days. The working standard purity was determined by HPLC with UV detection at $445 \mathrm{~nm}$. The purity, absorbance at $445 \mathrm{~nm}$ and the molar absorption coefficient $\left(\mathrm{E}_{1 \mathrm{~cm}}^{1 \%}: 2,550\right.$ at $445 \mathrm{~nm}$ in ethanol) [13] were used to calculate the concentration of the working standard. Dilutions of the working standard solution in ethanol were prepared daily to yield concentrations bracketing the levels of fortification. Aliquots of the standard dilutions were carried through the extraction protocol.

Sample Preparation. Formula powders were accurately weighed $(200 \mathrm{mg})$ into test tubes, mixed with 1.0 $\mathrm{mL}$ deionized $\mathrm{H}_{2} \mathrm{O}$ followed by mixing with $1.0 \mathrm{~mL}$ absolute ethanol. For liquid formulas, $1.0 \mathrm{~mL}$ ethanol was added to $1.0 \mathrm{~mL}$ aliquots of formula. Hexane:THF $(2.0$
$\mathrm{mL}$ ) was added to the samples and the tubes were shaken on a reciprocating shaker (Eberbach Corporation, Ann Arbor, MI) for 15 minutes. The tubes were centrifuged 15 minutes at $3500 \mathrm{rpm}$ and the upper organic layer was transferred to another test tube. The extraction was repeated and the organic phases combined. These combined phases were extracted with ethanol: $\mathrm{H}_{2} \mathrm{O}(2.0 \mathrm{~mL})$, briefly mixed on a vortex (Digital Pulse Mixer, Glas-Col, Terre Haute, IN), shaken again for 10 minutes and centrifuged for 5 minutes at 3,500 rpm. The lower aqueous layer was transferred to another test tube and the extraction was repeated and the aqueous phases combined. The combined aqueous phases were evaporated to dryness with nitrogen and heat $\left(30^{\circ} \mathrm{C}\right.$ to $\left.35^{\circ} \mathrm{C}\right)$.

Calibration Standards. Deionized $\mathrm{H}_{2} \mathrm{O}(1.0 \mathrm{~mL})$ was added to $1.0 \mathrm{~mL}$ aliquots of the working standard dilutions. The standards were then carried through the extraction protocol with the samples beginning with the addition of $2.0 \mathrm{~mL}$ hexane:THF. Following evaporation to dryness, the sample and standard extracts were dissolved in $1.0 \mathrm{~mL}$ mobile phase, MeOH:MTBE, 85:15, v:v. Samples were vortexed and allowed to stand until clear. Samples were transferred to amber vials for HPLC analyses, leaving behind any insoluble lipid material. The areas of the standard lutein peaks were plotted against lutein concentration; the regression equation was calculated and used to calculate the amount of lutein in the samples.

Chromatography conditions. The HPLC system was an Agilent 1100 Series coupled with a Variable Wavelength Detector (Little Falls, DE). Chromatographic separation was performed using a C30 carotenoid column, $5 \mu \mathrm{m}, 4.6 \times 250 \mathrm{~mm}$, (YMC, Wilmington, NC). The mobile phase was (A) $\mathrm{MeOH}$ and (B) MTBE. A step-wise linear elution gradient was used: Initially $85 \%$ A to $70 \%$ $\mathrm{A}$ at $18 \mathrm{~min}$, then decreased to $10 \% \mathrm{~A}$ within $1 \mathrm{~min}$, held for $4 \mathrm{~min}$, then increased to $85 \% \mathrm{~A}$ within $1 \mathrm{~min}$. The column was re-equilibrated at $85 \% \mathrm{~A}$ for $6 \mathrm{~min}$. Analyses were conducted with a flow rate of $1.0 \mathrm{~mL} / \mathrm{min}$ and lutein was quantified by measuring the absorbance at 445 $\mathrm{nm}$. Total run time was $30 \mathrm{~min}$. Representative chromatograms of lutein reference material and extracts of infant formula are shown in Figures $\mathbf{1}$ and 2, respectively.

\section{Results and Discussion}

Due to the high levels of lipids in milks and formulas, carotenoids analyses typically utilize a saponification step or an enzymatic digestion to separate the carotenoids from the lipid fraction [14-16]. This alkaline hydrolysis can lead to significant losses (up to $40 \%$ ) of the polar xanthophylls, including lutein [16]. Our method is a modification of the Schweigert method for carotenoids extraction which extracted the xanthophyll fraction with 


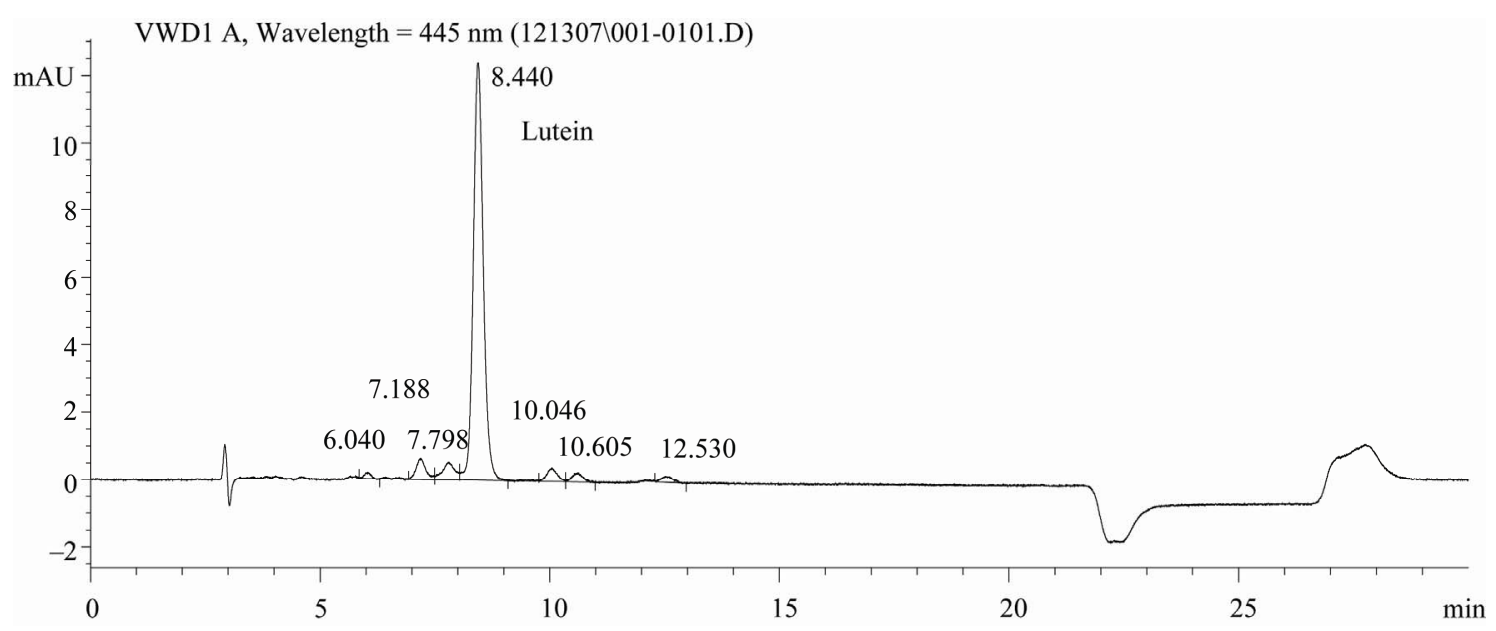

Figure 1. Chromatogram of lutein reference material, C30 carotenoid column, $5 \mu \mathrm{m}, 4.6 \times 250 \mathrm{~mm}$, detection at $445 \mathrm{~nm}$.

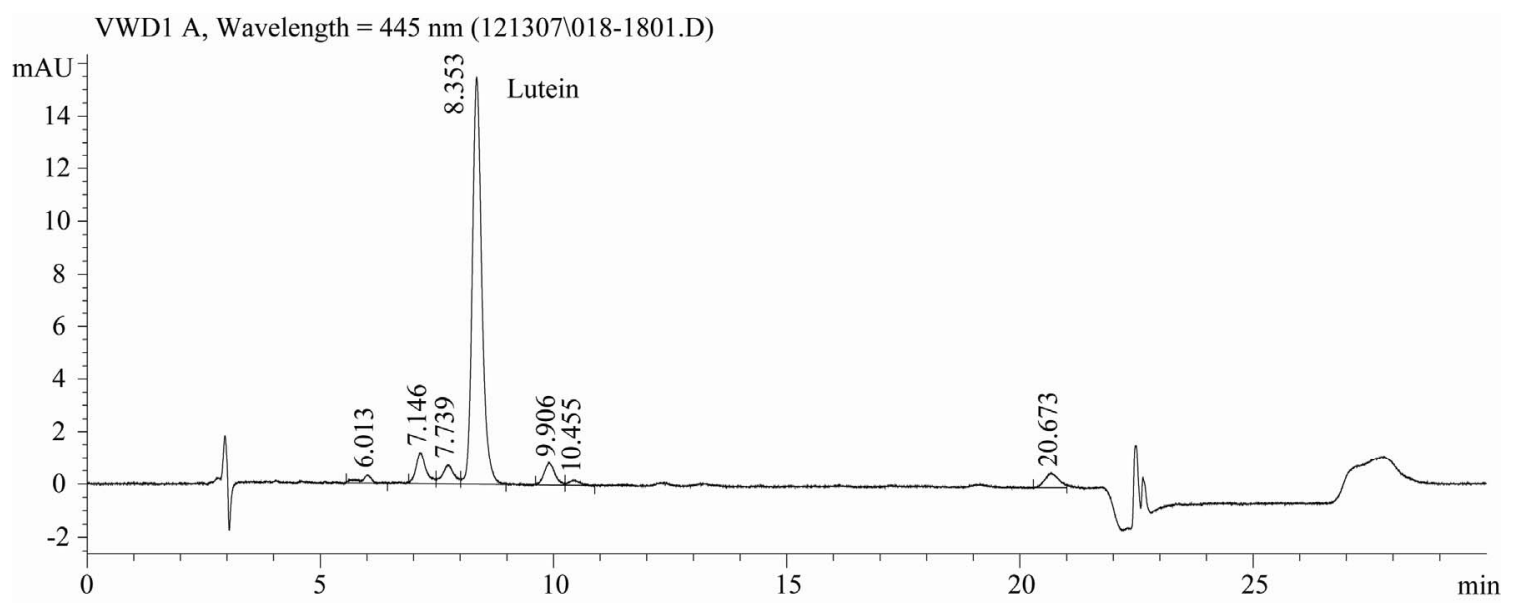

Figure 2. Chromatogram of lutein extracted from infant formula, $\mathrm{C} 30$ carotenoid column, $5 \mu \mathrm{m}, 4.6 \times 250 \mathrm{~mm}$, detection at 445 nm.

hexane prior to the saponification step [12].

Several protocols were investigated before the optimal method was achieved. Results for the preliminary methods are presented in Table 1. Initially, quantitation was by external standardization. Recoveries of lutein were low. The method was modified to incorporate THF into the hexane extraction step to improve xanthophyll extraction efficiency and recoveries improved. Echininone was added as an internal standard and initially recoveries were acceptable. Subsequent studies demonstrated the echininone internal standard was not recovered reproducibly at a level similar to the analyte of interest, lutein (data not shown). The difference in extraction efficiency resulted in recovery values for lutein that were in excess of $120 \%$. This was not acceptable in this application.

Ultimately, the calibration curve was constructed using lutein reference material diluted to concentrations brack- eting the two levels of fortification and carried through the extraction protocol. The correlation coefficient, $\mathrm{R}^{2}$, of the standard calibration curve was an average 0.997 over 8 runs.

Precision. Selected samples of lutein fortified products were analyzed in replicate and the relative standard deviation, $\mathrm{RSD}_{\mathrm{r}}$, of the results was determined. The acceptability criteria for within-day repeatability were $\mathrm{RSD}_{\mathrm{r}}<0.5$ of $\mathrm{RSD}_{\mathrm{H}}$, where $\mathrm{RSD}_{\mathrm{H}}$ is defined by the Horwitz equation: $\mathrm{RSD}_{\mathrm{H}}, \%=2 \mathrm{C}^{-0.1505}$, where $\mathrm{C}$ is the concentration as a decimal fraction in $\mathrm{g} / \mathrm{g}$ [17]. The predicted Relative Standard Deviations $\left(<0.5\right.$ of $\left.\mathrm{RSD}_{\mathrm{H}}\right)$ were $<$ $10.2 \%$ and $<7.5 \%$ for the $25 \mathrm{mcg} / \mathrm{L}$ and $200 \mathrm{mcg} / \mathrm{L}$ fortification levels, respectively. Repeatability results for both the low and high fortification levels are presented in Table 2. The within day repeatability results met the acceptability criteria, $\mathrm{RSD}_{\mathrm{r}}<0.5$ of $\mathrm{RSD}_{\mathrm{H}}$. 
Acceptance criteria for intermediate precision $\left(\mathrm{iRSD}_{\mathrm{R}}\right)$ over three separate days of analyses was defined as Table 1. Comparison of recovery of lutein between three trial methods.

\begin{tabular}{cccc}
\hline Calibration & Extraction solvent & \% Recovery $^{a}$ & $\mathrm{n}$ \\
\hline External standardization & Hexane & $65.8 \pm 8.7$ & 6 \\
External standardization & Hexane: THF & $89.1 \pm 6.5$ & 15 \\
Internal standardization & Hexane: THF & $98.3 \pm 7.7$ & 12 \\
\hline${ }^{a}$ mean \pm relative standard deviation. & & &
\end{tabular}

Table 2. Results of lutein analyses for intraassay precision (RSDr) \%.

\begin{tabular}{cccccc}
\hline Product & Category & $\begin{array}{c}\mathrm{Mean}^{\mathrm{a}} \\
\mathrm{mcg} / \mathrm{L}\end{array}$ & $\mathrm{RSD}_{\mathrm{r}} \%$ & $\mathrm{RSD}_{\mathrm{H}} \%$ & $\begin{array}{c}\mathrm{HORRAT} \\
\text { ratio }^{b}\end{array}$ \\
\hline S26 gold & $\begin{array}{c}\text { Infant } \\
\text { formula }\end{array}$ & 49.3 & 2.9 & 20.4 & 0.14 \\
Promil & $\begin{array}{c}\text { Follow-on } \\
\text { formula }\end{array}$ & 259.8 & 2.1 & 14.9 & 0.14 \\
Progress & $\begin{array}{c}\text { Toddler } \\
\text { milk }\end{array}$ & 280.6 & 3.3 & 14.9 & 0.22 \\
\hline & $\begin{array}{c}\text { Milk for young } \\
\text { children }\end{array}$ & 281.2 & 2.2 & 14.9 & 0.15 \\
\hline
\end{tabular}

${ }^{a} \mathrm{~N}=6$ each matrix; ${ }^{b}$ Horrat ratio defines the acceptability criteria, $\mathrm{RSD}_{\mathrm{r}} / \mathrm{RSD}_{\mathrm{H}}<0.5$.

Table 3. Results of lutein analyses for within-lab intermediate precision $\left(\mathrm{iRSD}_{\mathrm{R}}\right)$.

\begin{tabular}{|c|c|c|c|c|c|}
\hline Brand & Category & $\begin{array}{l}\operatorname{Mean}^{a} \\
\text { mcg/L }\end{array}$ & $\mathrm{iRSD}_{\mathrm{R}} \%$ & $\mathrm{RSD}_{\mathrm{H}} \%$ & $\begin{array}{c}\text { HORRAT } \\
\text { ratio }^{b}\end{array}$ \\
\hline S26 gold & Infant formula & 49.2 & 18.6 & 20.4 & 0.91 \\
\hline Promil & $\begin{array}{c}\text { Follow-on } \\
\text { formula }\end{array}$ & 247.8 & 9.9 & 14.9 & 0.66 \\
\hline Progress & Toddler milk & 273.2 & 11.5 & 14.9 & 0.77 \\
\hline Promise & $\begin{array}{l}\text { Milk for young } \\
\text { children }\end{array}$ & 299.1 & 10.2 & 14.9 & 0.68 \\
\hline
\end{tabular}

${ }^{a} 3$ days, duplicate analyses; ${ }^{b}$ Horrat ratio defines the acceptability criteria, $\mathrm{iRSD}_{\mathrm{R}} / \mathrm{RSD}_{\mathrm{H}}<1.0$.

Table 4. Results for lutein recovery.

\begin{tabular}{ccccccc}
\hline Fortification level & \multicolumn{3}{c}{$25 \mathrm{mcg} / \mathrm{L}$} & \multicolumn{2}{c}{$200 \mathrm{mcg} / \mathrm{L}$} \\
\hline Level of spike & $50 \%$ & $100 \%$ & $150 \%$ & $50 \%$ & $100 \%$ & $150 \%$ \\
Innate (mcg/L) & 21.4 & 21.4 & 21.4 & 24.4 & 24.4 & 24.4 \\
Spike (mcg/L) & 13.2 & 24.7 & 37.8 & 107.2 & 198.5 & 301.0 \\
Theoretical (mcg/L) & 34.6 & 46.1 & 59.1 & 107.4 & 198.9 & 301.6 \\
Measured (mcg/L) & 33.0 & 44.5 & 60.6 & 132.4 & 233.7 & 294.5 \\
Recovery (\%) & 87.9 & 93.9 & 103.9 & 100.8 & 105.5 & 89.8 \\
Acceptance criteria, +/- 26 & $100 \%$ & $+/-28.5 \%$ & $100 \%$ & $+/-21.0 \%$ \\
\hline
\end{tabular}

$\mathrm{iRSD}_{\mathrm{R}}<\mathrm{RSD}_{\mathrm{H}}$. Predicted $\mathrm{iRSD}_{\mathrm{R}}$ were $20.4 \%$ and $14.9 \%$ for $25 \mathrm{mcg} / \mathrm{L}$ and $200 \mathrm{mcg} / \mathrm{L}$ fortification levels, respectively. Intermediate precision results met the acceptability criteria of $\mathrm{iRSD}_{\mathrm{R}}<\mathrm{RSD}_{\mathrm{H}}$ and are presented in Table 3 .

Recovery. Lutein was spiked into the sample matrix and carried through the extraction protocol. Recoveries of reference lutein spiked into samples at three levels $(50 \%, 100 \%$ and $150 \%)$ of the low fortification level, 25 $\mathrm{mcg} / \mathrm{L}$, ranged from $87.9 \%$ to $103.9 \%$. Recoveries of reference lutein spiked into samples at three levels $(50 \%$, $100 \%$ and $150 \%$ ) of the high fortification level, 200 $\mathrm{mcg} / \mathrm{L}$, ranged from $89.8 \%$ to $105.5 \%$. Recovery results for both the low and high lutein fortification levels are presented in Table 4.

Ruggedness. This method for the measurement of lutein in fortified infant formulas and toddler milks was successfully transferred and validated at several quality assurance and contract laboratories.

In conclusion, this method was developed to measure the lutein content of fortified term and follow on formula as well as toddler milk and milk for young children. It was shown to be rugged, precise and accurate at lutein fortifications of $25 \mathrm{mcg} / \mathrm{L}$ and $200 \mathrm{mcg} / \mathrm{L}$.

\section{REFERENCES}

[1] S. Vilapando and M. Hamosh, "Early and Late Effects of Breast Feeding; Does Breastfeeding Really Matter?" Biology of the Neonate, Vol. 74, No. 2, 1998, pp. 177-191. doi:10.1159/000014022

[2] K. M. Bernt and W. A. Walker, "Human Milk as a Carrier of Biochemical Messages," Acta Paediatrica (Supplement), Vol. 88, No. 430, 1999, pp. 27-41.

[3] F. Granado, B. Olmedilla and I. Blance, "Nutritional and Clinical Relevance of Lutein in Human Health," British Journal of Nutrition, Vol. 90, No. 3, 2003, pp. 487-502. doi:10.1079/BJN2003927

[4] L. M. Canfield, M. T. Clandinin, D. P. Davies, M. C. Fernandez, J. Jackson, J. Hawkes, W. J. Goldman, K. Pramuk, H. Reyes, B. Sablan, T. Sonobe and X. Bo, "Multinational Study of Major Breast Milk Carotenoids of Healthy Mothers," European Journal of Nutrition, Vol. 42, No. 3, 2003, pp. 133-141.

[5] D. M. Snodderly, "Evidence for Protection against Age-related Macular Degeneration by Carotenoids and Antioxidant Vitamins," American Journal of Clinical Nutrition, Vol. 62 (supplement), 1995, pp. 1448S-1461S.

[6] W. Schalch, P. Dayhaw-Barker and F. M. Barker, "The Carotenoids of the Human Retina," In: A. Taylor, Ed., Nutritional and Environmental Influences of the Eye, Boca Raton, Fla: CRC Press, 1999, pp. 215-250.

[7] J. Dillon, L. Zheng, J. C. Merriam and E. R. Gaillard, "Transmission of Light to the Aging Human Retina: Possible Implications for Age Related Macular Degeneration," Experimental Eye Research, Vol. 79, No. 6, 2004, pp. 753-759. doi:10.1016/j.exer.2004.06.025

[8] F. Barker, M. Neuringer, E. Johnson, W. Schalch, W. Koepcke and D. M. Snodderly, "Dietary Zeaxanthin or Lutein Improves Foveal Photo-Protection from Blue Light in Xanthophyll-Free Monkeys," Investigative Ophthalmology \& Visual Science, Vol. 46, 2005, E-Abstract 1770 .

[9] F. Khachik, P. S. Bernstein and D. L. Garland, "Identification of Lutein and Zeaxanthin Oxidation Products in 
Human and Monkey Retinas," Investigative Ophthalmology \& Visual Science, Vol. 38, 1997, pp. 1802-1811.

[10] B. R. Hammond, B. R. Wooten and J. Curran-Celentano, "Carotenoids in the Retina and Lens: Possible Acute and Chronic Effects on Human Visual Performance," Archives of Biochemistry and Biophysics, Vol. 385, No. 1, 2001, pp. 41-46.

[11] L. Rapp, S. Maple and J. Choi, "Lutein and Zeaxanthin Concentrations in Rod Outer Segment Membranes from Perifoveal and Peripheral Human Retina," Investigative Ophthalmology \& Visual Science, Vol. 41, 2000, pp. 1200-1209.

[12] F. J. Schweigert, A. Hurtienne and K. Bathe, "Improved Extraction Procedure for Carotenoids from Human Milk," International Journal for Vitamin and Nutrition Research, Vol. 70, No. 3, 2000, pp. 79-83. doi:10.1024/0300-9831.70.3.79

[13] Y. Lui, M. J. Xu and L. M. Canfield, "Enzymatic Hydrolysis, Extraction, and Quantitation of Retinol and Major Carotenoids in Mature Human Milk," The Journal of Nutritional Biochemistry, Vol. 9, No. 3, 1998, pp. 178-183. doi:10.1016/S0955-2863(97)00183-6

[14] J. G. Jackson, E. L. Lien, S. J. White, N. J. Bruns and C. F. Kuhlman, "Major Carotenoids in Mature Human Milk: Longitudinal and Diurnal Patters," The Journal of Nutritional Biochemistry, Vol. 9, No. 1, 1998, pp. 2-7.
doi:10.1016/S0955-2863(97)00132-0

[15] V. C. Jewell, C. B. D. Tubman, C. A. Northrop-Clewes and D. I. Thurnham, "A Comparison of Lutein and Zeaxanthin Concentrations in Formulas and Human Milk Samples from Northern Ireland Mothers," European Journal of Clinical Nutrition, Vol. 58, 2004, pp. 90-97. doi:10.1038/sj.ejen.1601753

[16] M. Grosjean, "Carotenoids," Vol 1B: Spectroscopy, In: G. Britton, S. Liaaen-Jensen and H. Pfander, Eds., 1995, ISBN: 3-7643-2909-2, ISBN: 0-8176-2909-2.

[17] F. Khachik, C. J. Spangler, J. C. Smith, L. M. Canfield, A. Steck and H. Pfander, "Identification, Quantification, and Relative Concentrations of Carotenoids and Their Metabolites in Human Milk and Serum," Analytical Chemistry, Vol. 69, 1997, pp. 1873-1881. doi:10.1021/ac961085i

[18] A. R. Giuliano, E. M. Neilson, B. E. Kelly and L. M. Canfield, "Simultaneous Quantitation and Separation of Carotenoids and Retinol in Human Milk by High-Performance Liquid Chromatography," Methods in Enzymology, Vol. 213, 1992, pp. 391-399. doi:10.1016/0076-6879(92)13141-J

[19] W. Horwitz and G. W. Latimer, "Official Method of Analysis of AOAC International (Appendix E: Laboratory Quality Assurance)," 18th Edition, Association of Official Analytical Chemists, 2005. 